\title{
Intradialytic Hypotension: Beyond Hemodynamics
}

\author{
J. HAJAL ${ }^{1}$, N. JOUBRAN ${ }^{2}$, G. SLEILATY ${ }^{3}$, D. CHACRA $^{3}$, Y. SALIBA $^{1}$, S. ASSAAD $^{4}$, \\ D. CHELALA ${ }^{3 *}$, N. FARÈS ${ }^{1^{*}}$ \\ * These authors contributed equally to this work.
}

${ }^{1}$ Physiology and Pathophysiology Research Laboratory, Pole of Technology and Health, Faculty of Medicine, Saint Joseph University, Beirut, Lebanon, ${ }^{2}$ Faculty of Medicine and Medical Sciences, Saint Georges Hospital, Balamand University, Beirut, Lebanon, ${ }^{3}$ Faculty of Medicine, CHU Hotel Dieu de France Hospital, Saint Joseph University, Beirut, Lebanon, ${ }^{4}$ Faculty of Sciences, Section 2, Lebanese University, Beirut, Lebanon

Received November 12, 2018

Accepted May 7, 2019

Epub Ahead of Print August 19, 2019

\begin{abstract}
Summary
Intradialytic Hypotension is a major complication during hemodialysis session, associated with increased risk of cardiovascular events and mortality. Its pathophysiology is believed to be multifactorial and remains not well elucidated. The aim of this study is to put forward new mechanisms behind the development of intradialytic hypotension. The study included sixty-five subjects on chronic hemodialysis, divided into two groups: intradialytic hypotensive $(n=12)$ and normotensive $(n=53)$, according to the variation of systolic blood pressure between post-dialysis and pre-dialysis measurements. Renin and angiotensin converting enzyme I plasma concentrations increased in both groups but more likely in normotensive group. Aldosterone plasma concentration is increased in the normotensive group while it decreased in the intradialytic hypotension group. Plasma endothelin concentrations showed higher values in intradialytic hypotension group. Post-dialysis asymmetric dimethylarginine and angiotensin converting enzyme 2 plasma concentrations were significantly higher in intradialytic hypotension group as compared to normotensive one. Collectrin plasma concentrations were significantly lower in intradialytic hypotension group. Finally, post-dialysis vascular endothelial growth factor C plasma concentration significantly increased in intradialytic hypotension group. In conclusion, endothelial dysfunction characterized by a lower level of vasoactive molecule seems to play a critical role in intradialytic hypotension development.
\end{abstract}

\section{Key words}

Hemodialysis • Intradialytic hypotension • Endothelial dysfunction

- Collectrin • Vascular Endothelial Growth Factor C

\section{Corresponding author}

N. Farès, Physiology and Pathophysiology Research Laboratory, Pole of Technology and Health, Faculty of Medicine, Saint Joseph University, P.O. Box 5208-17, Beirut, Lebanon. E-mail: nassim.fares@usj.edu.lb

\section{Introduction}

Intradialytic Hypotension (IHO) is the most common complication occurring in 5 and $30 \%$ of hemodialysis (HD) sessions (Chou et al. 2017). The National Kidney Foundation's Kidney Disease Outcomes Quality Initiative (KDOQI) guidelines and the 2007 European best practices guidelines (Kooman et al. 2007), define IHO as a decrease in either systolic blood pressure (SBP) by more than $20 \mathrm{~mm} \mathrm{Hg}$ or mean arterial pressure by more than $10 \mathrm{~mm} \mathrm{Hg}$, associated with symptoms of hypoperfusion including nausea, vomiting, abdominal discomfort yawning, sighing, muscle crumps, restlessness, dizziness, fainting and anxiety (K/DOQI Workgroup 2005, Gul et al. 2016). IHO is known to lead impairment of patient's quality of life (Ronco et al. 2000). In addition, frequent episodes of IHO may result in cardiovascular complications e.g. ischemic heart events, cardiac arrhythmia, and congestive heart failure 
(McIntyre 2010), leading to increased hospitalization, and increase in mortality rate (Inrig et al. 2007, Chou et al. 2017, Chou et al. 2018). Despite the different strategies in treating and preventing IHO (Reeves and Mc Causland 2018) (real-time hemodynamic monitoring, volumetric control, bicarbonate-based buffer, and biocompatible membranes), it remains a common and distressful event during HD procedure. In general, the pathophysiology of IHO is etiology dependent. Most of the studies suggest acute hypovolemia induced by rapid removal of blood volume as a major factor, along with an inadequate response of the cardiovascular system in reestablishing a normal blood volume (Daugirdas 2001, Palmer and Henrich 2008, Chou et al. 2017). Nevertheless, the pathophysiology of IHO is believed to be multifactorial. Therefore, therapeutic interventions to correct IHO should be more adjusted, taking into consideration all the pathophysiological mechanisms. The Renin Angiotensin Aldosterone system (RAAS), nitric oxide (NO) and other endothelial molecules are implicated in blood pressure control (Levine et al. 2012). Their role in the pathophysiology of IHO is not yet elucidated. Hence, the better understanding of the pathophysiological mechanisms underlying IHO could be of a great interest. The objective of our study is to assess the endothelial microenvironment molecules status in IHO patients in order to better understand the pattern of this entity and to pinpoint new therapeutic strategies.

\section{Methods}

\section{Study design outcome}

The protocol was approved by the Ethical Committee of the Saint Joseph University and the Hotel Dieu de France University Hospital (Beirut) according to the declaration of Helsinki. All HD patients within the dialysis unit of the tertiary university hospital (Hotel Dieu de France, Beirut) were invited to take part of this study. The criteria to be eligible for the study were patients on chronic HD, >18 years of age, medically stable, undergoing hemodialysis three times per week for a minimum of $4 \mathrm{~h}$ per session and for more than 6 months. Patients with active infection, pulmonary diseases, heart failure (left ventricular ejection fraction $<50 \%$ ), cancer, or any other terminal illness were excluded from the study. 80 patients were initially eligible for the study, 65 subjects were enrolled following inclusion/exclusion criteria (Fig. 1).

Dialytic session data were recorded for three months period study, on a session-to-session basis. Laboratory parameters were measured monthly. Body temperature and heart rate were taken before and after each HD session. Excess weight at the start of dialysis was defined as the difference between pre-dialysis weight and dry weight. The prescribed ultrafiltration (UF) volume was calculated by adding the estimated intradialytic fluid intake (usually $500-750 \mathrm{ml}$ ) to the excess weight. However, for all analyses, the exact UF volume as delivered by the dialysis apparatus was used. Blood pressure was monitored using an automated sphygmomanometer integrated in the dialysis B Braun machine, before, hourly during and immediately following the dialysis session or when hypotensive symptoms occur. Pre-dialysis blood pressure was measured in the non-access arm at the beginning of HD after 10-minutes rest with the patient seated in the dialysis chair before placement of a dialysis needle. Postdialysis blood pressure was measured at the end of the session, 10-minutes after disconnecting the patient from the dialysis circuit.

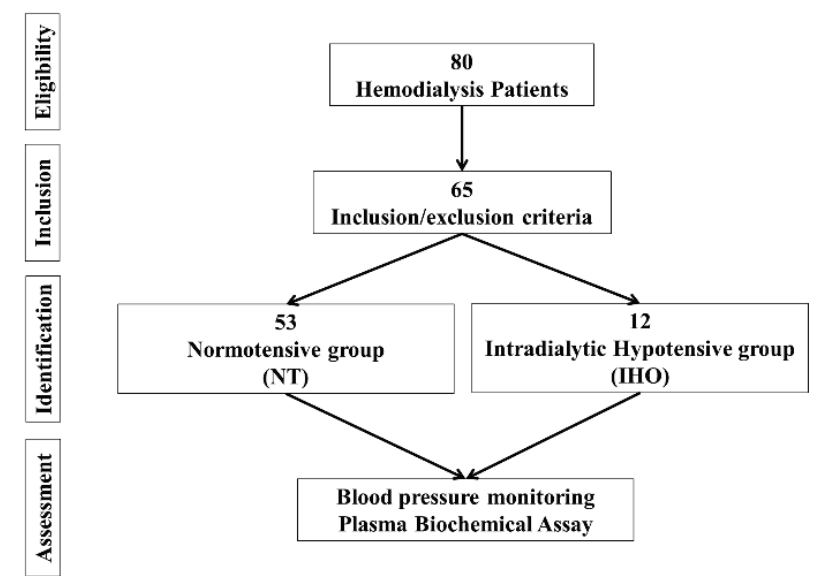

Fig. 1. Flow chart of patient selection.

\section{HD settings}

HD modalities were kept constant during the whole study period. All the sessions consisted of standard HD using standard dialysis solutions, with bicarbonate buffer. The dialyzer used was "Renak" 1.5 to $1.8 \mathrm{~m}^{2}$. HD was performed in the regular setting in a quiet room. Adequacy of dialysis was assessed using $\mathrm{KT} / \mathrm{V}$, calculated as the natural logarithm of the ratio between initial and final urea concentration. Dialysate sodium concentration was the same for all the patients at $140 \mathrm{meq} / \mathrm{l}$. The amount of UF was recorded for every patient in every session. Session UF rate was calculated 
from the target UF volume at the start of each session $(\mathrm{ml})$, per body weight $(\mathrm{kg})$, per dialysis session length (h). Average UF rate for sessions delivered during the exposure period was calculated for each patient. No UF profile was used.

\section{Data collection and description}

Patient's demographic characteristics were obtained from the hospital electronic medical record, such as age, gender, dialysis vintage and initial nephropathy. The pulse pressure was calculated as the difference between the systolic and diastolic blood pressure for each pre- and post-dialysis session. Laboratory values and dialytic session characteristics taken during the study period were considered as the mean value measured during the exposure period. Prescribed antihypertensive medications were also considered, and it was not changed for the purposes of the study. The number of IHO episodes in 36 consecutive HD sessions was recorded for each patient. When hypotensive episodes occurred, the responsive measures included saline administration or premature cessation of dialysis.

\section{Categorization of groups for analysis}

The study patients were divided into two groups according to average SBP variation between post- and predialysis values during 36 consecutive HD sessions: IHO group included patients who had their post-dialysis SBP dropped under $100 \mathrm{~mm} \mathrm{Hg}$ with clinical symptoms during HD, for at least $50 \%$ of HD sessions; Normotensive (NT) group included patients who did not have a major change in average post- and pre- dialysis SBP.

\section{Plasma biochemical assays}

During the study period, immediately before and at the end of each HD session, whole blood samples were collected in EDTA tubes, directly from vascular access. Whole blood was centrifuged at 4,500 RPM for $10 \mathrm{~min}$. Plasma were aliquoted and stored at $-80^{\circ} \mathrm{C}$ for plasma biochemical assays to avoid freeze-thaw cycles.

The concentrations of different biochemical molecules were measured before and after HD sessions using enzyme-linked immunosorbent assay (ELISA) kits for NT and IHO groups, following the instructions of the manufacturers. No significant cross-reactivity or interference was observed in any kit.

Tumor necrosis factor $\alpha$ (TNF- $\alpha)$, Vascular Endothelial Growth Factor C (VEGF-C), endothelin 1
(ET-1), angiotensin converting enzyme type I (ACE I), aldosterone and renin ELISA kits were provided from R\&D Systems Kits (R\&D system Inc. Minneapolis, MN, USA) with a detection range: $0.5-5.5 \mathrm{pg} / \mathrm{ml}$, 4.0-48.4 pg/ml, $0.031-0.207 \mathrm{pg} / \mathrm{ml}, \quad 0.008-0.051 \mathrm{ng} / \mathrm{ml}$, $7.74-22.4 \mathrm{pg} / \mathrm{ml}$ and $0.769-14.8 \mathrm{pg} / \mathrm{ml}$ respectively; and intra- and inter-assay coefficients of variation: $5.2-7.4 \%$, 6.6-8.5\%, 4.0-7.6\%, 3.4-7.7\%, 3.4-12.1\% and 5.3-5.5\% respectively. Asymmetric dimethylarginine (ADMA) and L-Citrulline ELISA kits were provided by Immunodiagnostik (Immunodiagnostik AG, Bensheim, Germany) with a detection range: $0.26-0.64 \mu \mathrm{mol} / 1$ and $1.5 \mu \mathrm{mol} / 1$ respectively; and intra- and inter-assay coefficients of variation: 5.8-7.6\% and 1.3-3.0\% respectively. Angiotensin Converting Enzyme 2 (ACE 2) was provided by IBL (Immuno-Biological Laboratories, Inc. Minneapolis, MN, USA) with a detection range: $62.5-4,000 \mathrm{pg} / \mathrm{ml}$. Collectrin was provided by Cusabio (Cusabio Biotech CO., LTD, Wuhan, Hubei, China) with a detection range $51-800 \mathrm{pg} / \mathrm{ml}$, and intra- and inter-assay coefficients of variation less than $15 \%$ and less than $15 \%$, respectively.

C-reactive protein (CRP) was delivered by Abcam (Abcam, Cambridge, UK) with a minimal detectable dose of $4 \mathrm{pg} / \mathrm{ml}$; and intra- and inter-assay coefficients of variation 5-3\%.

\section{Statistical methods}

Categorical data were reported as percentages and were compared using $\mathrm{Chi}^{2}$ test or Fisher exact test as appropriate. Shapiro-Wilk and Kolmogorov-Smirnov tests were used to assess significant departure of continuous variables from normality. For variables with non-Gaussian distribution, the median with its interquartile range was used. For variables not departing significantly from normality, mean \pm standard deviation was reported. Ordinal variables were compared using Mann-Whitney U test. For non-repeated measures, the student $t$-test was used. A repeated-measure multivariable analysis of variance model (MANOVA) was used to assess the variation of the dependent variables (DVs) (plasmatic levels of the different markers, and clinical parameters: SBP, heart rate, temperature), with one within factor (time defined as either pre or post-dialysis), and one between factor (group, NT or IHO groups). The interaction group*time was prespecified in the model. Univariate $\mathrm{F}$ tests were then conducted for individual DVs at the $5 \%$ level. Due to the non-random design and the unbalanced group sizes, type III sum of squares was 
used. MANOVA was performed using SPSS v22 (IBM Corp. Released 2013. IBM SPSS Statistics for Windows, Version 22.0. Armonk, NY: IBM Corp.).

\section{Results}

Participant's characteristics and SBP classification

Thirty eight men and twenty seven women completed the study period, their baseline demographics are presented in Table 1. Among the 65 HD subjects included in the study, 53 patients were NT and 12 patients experienced IHO, representing $19 \%$ of the study population. During the study period, $432 \mathrm{HD}$ sessions in IHO group were examined for IHO episodes by comparing post-dialytic with pre-dialytic blood pressure measurements and by evaluating symptoms of hypotension. The average intradialytic variation in SBP calculated as the difference between post- and predialysis shows a clear difference between the two groups, with $-16.76 \pm 8.53 \mathrm{~mm} \mathrm{Hg}$ among NT and $-36.50 \pm 8.12 \mathrm{~mm} \mathrm{Hg}$ among IHO. SBP decreases at postdialysis in both groups, but was significantly lower in IHO compared to NT group ( $p$ (interaction) $<0.001$, Table 1).

Table 1. Analytic characterization and clinical patient's data.

\begin{tabular}{|c|c|c|c|c|}
\hline \multicolumn{2}{|l|}{ Variables } & \multirow{2}{*}{$\frac{\text { NT }(\mathbf{n}=\mathbf{5 3})}{74(63-80)}$} & \multirow{2}{*}{$\begin{array}{l}\text { IHO }(\mathbf{n}=\mathbf{1 2}) \\
76(56.5-79)\end{array}$} & \multirow{2}{*}{$\frac{\boldsymbol{p} \text { value }}{0.910}$} \\
\hline Age (y) & & & & \\
\hline Gender $(M / W)$ & & $32 / 21$ & $6 / 6$ & 0.534 \\
\hline Dialysis vintage (y) & & $8.05 \pm 4.07$ & $10.83 \pm 3.16$ & 0.100 \\
\hline Session duration $(h)$ & & $4.5(4-5)$ & $4.15(4-4.26)$ & 0.015 \\
\hline \multirow{2}{*}{ Vascular access (\%) } & Fistula & $49(92)$ & $11(91)$ & 0.629 \\
\hline & Jugular catheter & $4(8)$ & $1(9)$ & 0.533 \\
\hline \multirow[b]{2}{*}{ Mean SBP } & Pre-dialysis & $136 \pm 11.59$ & $126 \pm 12.4$ & $p($ time $)<0.001$ \\
\hline & Post-dialysis & $119 \pm 8.03$ & $89 \pm 3.32$ & $\begin{array}{c}p(\text { group })<0.001 \\
p(\text { interaction })<0.001\end{array}$ \\
\hline \multirow[b]{2}{*}{ Mean pulse pressure } & Pre-dialysis & $63.87 \pm 10.06$ & $55.54 \pm 6.76$ & $p($ time $)<0.001$ \\
\hline & Post-dialysis & $54.59 \pm 8.78$ & $29.56 \pm 2.87$ & $\begin{array}{c}p(\text { group })<0.001 \\
p(\text { interaction })<0.001\end{array}$ \\
\hline \multicolumn{5}{|c|}{ Nephropathy origin (\%) } \\
\hline Hypertension & & $20(38)$ & $1(8)$ & 0.085 \\
\hline Diabetes mellitus & & $15(28)$ & $2(16)$ & 0.494 \\
\hline Glomerulonephritis & & $7(13)$ & $2(16)$ & 0.667 \\
\hline Polycystic kidney dise & & $4(8)$ & $3(25)$ & 0.111 \\
\hline Chronic tubulo-inters & itial nephritis & $4(8)$ & $1(8)$ & 0.999 \\
\hline Unknown & & $3(5)$ & $3(25)$ & 0.071 \\
\hline \multicolumn{5}{|l|}{ Risk factors (\%) } \\
\hline Smoking & & $28(53)$ & $3(25)$ & 0.113 \\
\hline Dyslipidemia & & $27(51)$ & $7(58)$ & 0.754 \\
\hline Diabetes & & $16(30)$ & $3(25)$ & 0.999 \\
\hline Obesity & & $13(24)$ & $3(25)$ & 0.999 \\
\hline Sedentary lifestyle & & $14(26)$ & $1(8)$ & 0.267 \\
\hline Alcohol & & $4(7)$ & $2(16)$ & 0.305 \\
\hline Previous coronary ar & ery disease & $17(32)$ & $3(25)$ & 0.652 \\
\hline Stroke & & $2(4)$ & $0(0)$ & 0.333 \\
\hline Peripheral vascular $d$ & isease & $10(19)$ & $2(17)$ & 0.909 \\
\hline \multicolumn{5}{|c|}{ Antihypertensive medication (\%) } \\
\hline$A R B$ & & $14(26)$ & $3(25)$ & 1.000 \\
\hline$\beta$ blockers & & $32(60)$ & $9(75)$ & 0.737 \\
\hline$C C B$ & & $34(64)$ & $5(41)$ & 0.523 \\
\hline
\end{tabular}




\begin{tabular}{lccc}
\hline$\alpha$ blockers & $13(24)$ & $1(8)$ & 0.438 \\
$\alpha, \beta$ blockers & $2(3)$ & $2(16)$ & 0.152 \\
Diuretics & $19(35)$ & $0(0)$ & 0.013 \\
Vasodilators & $12(22)$ & $4(33)$ & 0.109 \\
\hline
\end{tabular}

Combination of antihypertensive drugs (\%)

\begin{tabular}{lccc}
\hline More than 2 combinations & $28(53)$ & $4(33)$ & 0.263 \\
\hline Laboratory data & & & \\
\hline Hematocrit (\%) & $32 \pm 3.67$ & $33.19 \pm 4.40$ & 0.347 \\
Hemoglobin (g/l) & $10.57 \pm 1.24$ & $10.93 \pm 1.49$ & 0.396 \\
Alkaline phosphatase (U/l) & $90(76.5-123.0)$ & $98(62-155.75)$ & 0.637 \\
Serum glutamic pyruvic transaminase (IU/l) & $24(19-27)$ & $24(21-29.5)$ & 0.623 \\
Parathyroid hormone (pg/ml) & $179(127-275)$ & $71.8(54.1-443.5)$ & 0.670 \\
Serum bicarbonate (mmol/l) & $21.92 \pm 3.17$ & $21.08 \pm 2.11$ & 0.386 \\
Serum phosphorus (mmol/l) & $1.56 \pm 0.46$ & $1.80 \pm 0.48$ & 0.118 \\
Serum calcium (mmol/l) & $2.26 \pm 0.15$ & $2.25 \pm 0.12$ & 0.694 \\
Urea reduction ratio & $0.75 \pm 0.06$ & $0.76 \pm 0.09$ & 0.537 \\
Creatinine ( $\mu$ mol/l) & $280.85 \pm 98$ & $299.55 \pm 87$ & 0.561 \\
\hline
\end{tabular}

Values are represented as mean $\pm \mathrm{SD}$ or as median with its interquartile range (IQR=Q1-Q3). The $t$-test, Mann-Whitney $U$ test and Fisher exact test were used as appropriate. Two-way MANOVA for repeated measures is represented by 3 types of $p$ values: $p$ (Time) associated with the within subject effect (Time factor, 2 levels, pre and post-dialysis), $p$ (Group) associated with the between subject's effect (Group factor, 2 levels, NT and IHO groups), and the $p$ (Interaction) associated with the group*time interaction term. NT: normotensive; IHO: Intradialytic Hypotension; SBP: systolic blood pressure; ARB: angiotensin II receptor blocker; CCB: calcium channel blockers; $n$ : number of patients in each group, y: years.

The demographic parameter did not differ significantly between the two groups (Table 1). The mean age was $74(63-80)$ in NT group and $76(56.5-79)$ in IHO group, median time on HD was $8.05 \pm 4.07$ years in NT group, and $10.83 \pm 3.16$ years in IHO group. Women comprised $65 \%$ of the NT group and $50 \%$ of IHO group. Hypertensive nephropathy was the most frequent cause of end stage kidney disease in NT group (38\%), while in IHO group it was the polycystic kidney disease (50\%). The catheter rate was the same in both groups (Table 1). The majority of patients were on antihypertensive medications, calcium channel blockers (CCB) and $\beta$ blockers were the most commonly prescribed. Laboratory measurements show no difference between the two groups (Table 1).

\section{Analytical measurements}

Dry weight was determined clinically with the help of echocardiography when needed by assessing the inferior vena cava diameter. Interdialytic weight gain and Intradialytic weight loss were comparable in both groups (Table 2), leaving the patients at their presumed dry weights. The body temperature and heart rate were comparable during HD sessions in both group (Table 2). Pre- and post-dialysis $\mathrm{Na}$ plasma concentrations were similar in both groups (Table 3 ). Serum K concentration followed the same progression in both groups, but was slightly higher in IHO group. UF rate was comparable between the two groups (Table 3). To determine the effect of UF, univariate Spearman's correlation was used to determine whether there were any significant associations between intradialytic SBP variation during HD sessions and UF rate in both groups. There was no direct association between change in SBP and UF rate in NT $(\mathrm{r}=0.164, p=0.240, \mathrm{n}=53$, Fig. 2A) and IHO groups $(\mathrm{r}=-0.231, p=0.456, \mathrm{n}=12$, Fig. $2 \mathrm{~B})$.

\section{RAAS markers assessment}

RAAS was evaluated by plasma concentration measurements of renin, ACE I, aldosterone and ACE 2. Comparing post- to pre-dialysis, renin, ACE I and ACE 2 plasma concentrations significantly increased in NT and IHO groups $\quad(p$ (time $)<0.001, \quad p$ (time $)<0.001 \quad$ and $p$ (time) $<0.001$ respectively, Fig. 3 ), with higher levels in NT group compared to IHO group for renin ( $p$ (interacttion $<0.001$, Fig. 3) and ACE I ( $p$ (interaction) $=0.002$, Fig. 3) plasma concentrations. However, post-dialysis ACE 2 plasma concentration was significantly higher in IHO group compared to NT group $(p$ (interaction $)=0.001$, Fig. 3). Aldosterone plasma concentration increased significantly in the NT group while it decreased in the IHO group ( $p$ (interaction) $<0.001$, Fig. 3 ) . 
Table 2. Pre- and post-dialysis clinical parameters measurements during each HD session over the study period.

\begin{tabular}{|c|c|c|c|c|}
\hline Parameters & & NT & IHO & $p$ value \\
\hline \multirow{2}{*}{ Mean body weight (kg) } & Pre-dialysis & $74.8 \pm 17.7$ & $75.16 \pm 13.94$ & 0.945 \\
\hline & Post-dialysis & $71.9 \pm 17.2$ & $72.70 \pm 13.26$ & 0.884 \\
\hline \multicolumn{2}{|c|}{$\begin{array}{l}\text { Mean Intradialytic weight loss (\% Intradialytic } \\
\text { weight loss) }\end{array}$} & $\begin{array}{c}2.86 \pm 0.88 \\
(3.87 \pm 1.01)\end{array}$ & $\begin{array}{c}2.51 \pm 1.00 \\
(3.29 \pm 0.96)\end{array}$ & $\begin{array}{c}0.225 \\
(0.075)\end{array}$ \\
\hline \multicolumn{2}{|c|}{$\begin{array}{l}\text { Mean Interdialytic weight gain (\% Interdialytic } \\
\text { weight loss) }\end{array}$} & $\begin{array}{c}2.80 \pm 0.99 \\
(3.95 \pm 1.28)\end{array}$ & $\begin{array}{c}2.51 \pm 0.93 \\
(3.46 \pm 1.12)\end{array}$ & $\begin{array}{c}0.348 \\
(0.220)\end{array}$ \\
\hline \multirow[t]{2}{*}{ Mean body temperature $\left({ }^{\circ} \mathrm{C}\right)$} & Pre-dialysis & $35.9 \pm 0.3$ & $35.97 \pm 0.28$ & $\begin{array}{l}p(\text { time })=0.090 \\
p(\text { group })=0.885\end{array}$ \\
\hline & Post-dialysis & $36.1 \pm 0.63$ & $36.09 \pm 0.27$ & $p($ interaction $)=0.553$ \\
\hline \multirow{2}{*}{ Mean heart rate (beats/min) } & Pre-dialysis & $72 \pm 8.67$ & $72.70 \pm 9.41$ & $\begin{array}{l}p(\text { time })=0.034 \\
p(\text { group })=0.620\end{array}$ \\
\hline & Post-dialysis & $73 \pm 7.49$ & $74.29 \pm 8.59$ & $p($ interaction $)=0.549$ \\
\hline
\end{tabular}

Values are represented as mean \pm SD. The student $t$-test was used for non-repeated measures. The Two-way MANOVA test was used for repeated measures, and is represented by 3 types of $p$ values: $p$ (Time) associated with the within subject effect (Time factor, 2 levels, pre and post-dialysis), $p$ (Group) associated with the between subject's effect (Group factor, 2 levels, NT and IHO groups), and the $p$ (Interaction) associated with the group*time interaction term. NT: normotensive; IHO: Intradialytic Hypotension.

Table 3. Biological forum and UF rate in NT and IHO groups.

\begin{tabular}{|c|c|c|c|c|}
\hline Markers & & NT & IHO & $p$ value \\
\hline \multicolumn{5}{|c|}{ ET-1 plasma concentrations } \\
\hline \multirow[b]{2}{*}{$E T-1(\mathrm{pg} / \mathrm{ml})$} & Pre-dialysis & $0.58 \pm 0.29$ & $2.48 \pm 1.63$ & \multirow{2}{*}{$\begin{array}{c}p(\text { time })=0.840 \\
p(\text { group })<0.001 \\
p(\text { interaction })=0.003\end{array}$} \\
\hline & Post-dialysis & $1.01 \pm 0.32$ & $2.02 \pm 1.21$ & \\
\hline \multicolumn{5}{|l|}{ Electrolytes } \\
\hline \multirow[b]{2}{*}{ Serum Na (mmol/l) } & Pre-dialysis & $138.70 \pm 3.47$ & $139.67 \pm 3.92$ & \multirow{4}{*}{$\begin{array}{c}p(\text { time })<0.001 \\
p(\text { group })=0.652 \\
p(\text { interaction })=0.495 \\
p(\text { time })<0.001 \\
p(\text { group })=0.237 \\
p(\text { interaction })=0.011\end{array}$} \\
\hline & Post-dialysis & $143.60 \pm 2.06$ & $143.55 \pm 2.42$ & \\
\hline \multirow{2}{*}{ Serum K (mmol/l) } & Pre-dialysis & $5.34 \pm 0.63$ & $5.97 \pm 0.76$ & \\
\hline & Post-dialysis & $3.43 \pm 0.29$ & $3.27 \pm 0.24$ & \\
\hline \multicolumn{5}{|c|}{ Inflammation markers plasma concentrations } \\
\hline \multirow[b]{2}{*}{$C R P(m g / l)$} & Pre-dialysis & $17.61 \pm 7.44$ & $21.24 \pm 7.60$ & \multirow{4}{*}{$\begin{array}{c}p(\text { time })=0.003 \\
p(\text { group })=0.216 \\
p(\text { interaction })=0.433 \\
p(\text { time })=0.486 \\
p(\text { group })=0.064 \\
p(\text { interaction })=0.959\end{array}$} \\
\hline & Post-dialysis & $18.11 \pm 8.03$ & $22.76 \pm 2.02$ & \\
\hline \multirow[b]{2}{*}{$T N F-\alpha(p g / m l)$} & Pre-dialysis & $12.90 \pm 2.49$ & $13.36 \pm 4.37$ & \\
\hline & Post-dialysis & $14.40 \pm 3.78$ & $17.25 \pm 5.55$ & \\
\hline \multicolumn{5}{|l|}{ UF rate } \\
\hline \multicolumn{2}{|c|}{$U F$ rate index $(\mathrm{ml} / \mathrm{h} / \mathrm{kg})$} & $12.99 \pm 3.17$ & $13.00 \pm 1.53$ & 0.866 \\
\hline \multicolumn{5}{|l|}{ Erythropoietin } \\
\hline \multicolumn{2}{|c|}{ Erythropoietin (UI/kg/week) } & $65.68 \pm 14.4$ & $78.07 \pm 30.69$ & 0.239 \\
\hline
\end{tabular}

Values are represented as mean $\pm \mathrm{SD}$. The student $t$-test was used for non-repeated measures. Two-way MANOVA for repeated measures is represented by 3 types of $p$ values: $p$ (Time) associated with the within subject effect (Time factor, 2 levels, pre and postdialysis), $p$ (Group) associated with the between subject's effect (Group factor, 2 levels, NT and IHO groups), and the $p$ (Interaction) associated with the group*time interaction term. NT: normotensive; IHO: Intradialytic Hypotension; RAAS: renin-angiotensinaldosterone system; ACE I: Angiotensin Converting Enzyme type I; ACE 2: Angiotensin Converting Enzyme type 2; Na: sodium; K: potassium; ET-1: Endothelin 1; CRP: C-reactive protein; TNF-a: Tumor Necrosis Factor a; UF: ultrafiltration. 


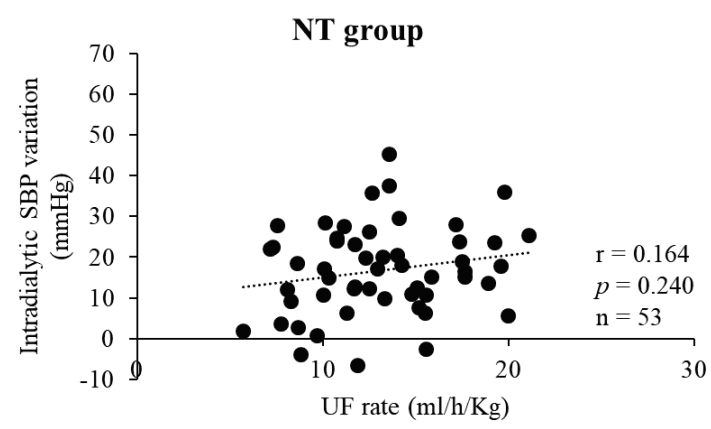

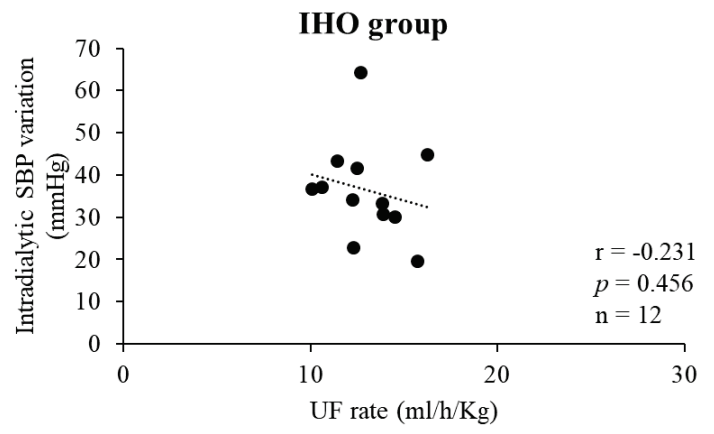

Fig. 2. Correlation between intradialytic SBP variation and UF rate in NT (A) and IHO (B) groups. Spearman's rank correlation $(r=0.164, p=0.240, n=53)$ for NT group, and $(r=-0.231, p=0.456, n=12)$ for IHO group. NT: normotensive; IHO: Intradialytic Hypotension; SBP: systolic blood pressure; UF: ultrafiltration.
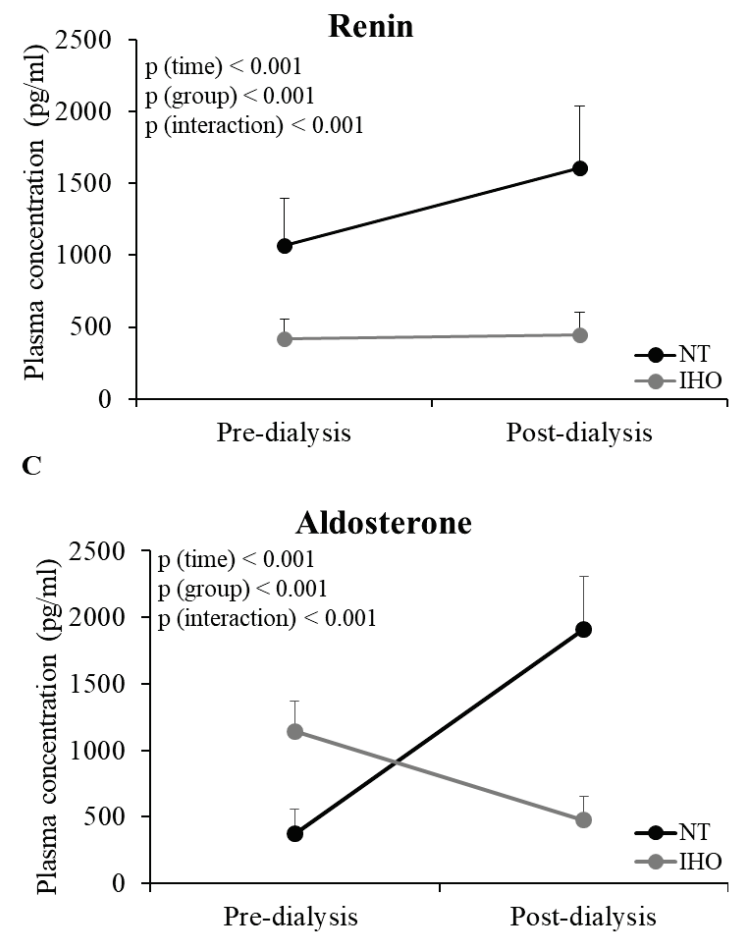

B
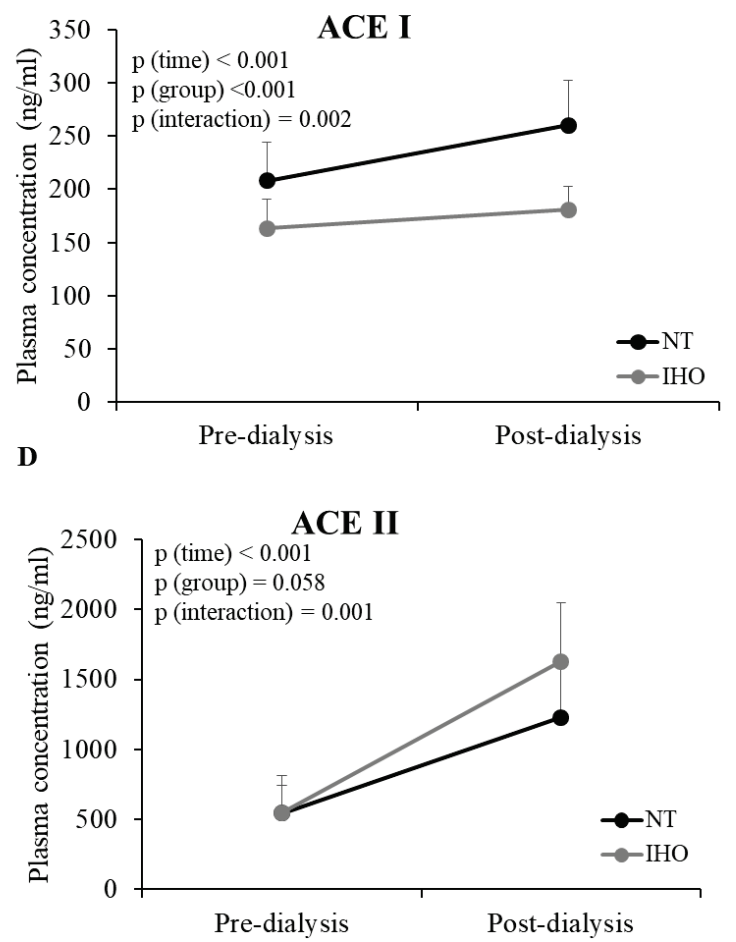

Fig. 3. RAAS evaluation in NT and IHO groups. Intradialytic changes of mean plasma concentrations of (A) Renin, (B) ACE I, (C) Aldosterone and (D) ACE 2 were measured between pre- and post-dialysis in NT and IHO groups. Values are represented as mean \pm SD. All the data were evaluated by the Two-way MANOVA for repeated measures and represented by 3 types of $p$ values: $p$ (Time) associated with the within subject effect (Time factor, 2 levels, pre and post-dialysis), $p$ (Group) associated with the between subject's effect (Group factor, 2 levels, NT and IHO groups), and the $p$ (Interaction) associated with the group*time interaction term. NT: normotensive; IHO: Intradialytic Hypotension; ACE I: angiotensin converting enzyme type I; ACE 2: Angiotensin Converting Enzyme 2.

\section{Inflammation markers}

Inflammatory markers were assessed by measuring CRP and TNF- $\alpha$ plasma concentrations; they increased in post-dialysis in both groups ( $p$ (time) $=0.003$, Table 3), no differences were detected between groups for CRP $(p$ (interaction) $=0.433$, Table 3$)$, and for TNF- $\alpha$ $(p$ (interaction $)=0.959$, Table 3$)$ plasma concentrations .

\section{ET-1, NO synthesis and VEGF-C plasma concentration} assessment

Pre- and post-dialysis ET-1 plasma concentration increased significantly in IHO group compared to NT group ( $p$ (group) $<0.001, \quad p$ (interaction) $=0.003$, Table 3 ). NO synthesis control involves ADMA (NO synthase inhibitor) and L-Citrulline which is secreted in equimolar amounts to $\mathrm{NO}$ and Collectrin 
(L-Arginine uptake enhancer). Post-dialysis L-Citrulline plasma concentration significantly decreased in both groups ( $p$ (time) $<0.001$, Fig. 4A). Post-dialysis ADMA plasma concentration was significantly higher in IHO group compared to NT group ( $p$ (group) $=0.001$, Fig. 4B). Whereas, pre- and post-dialysis Collectrin plasma concentrations were significantly lower in IHO group compared to NT group $\quad(p$ (time $)<0.001$, $p($ group $)=0.002, \quad \mathrm{p}($ interaction $)=0.057, \quad$ Fig. $4 \mathrm{C}) . \quad$ In NT group, VEGF-C plasma concentration slightly increased in post-dialysis compared to pre-dialysis, while in IHO group, the increase was more pronounced (p (time) $<0.001$, Fig. 4D). Post-dialysis VEGF-C plasma concentration significantly increased in IHO group compared to NT group.
A

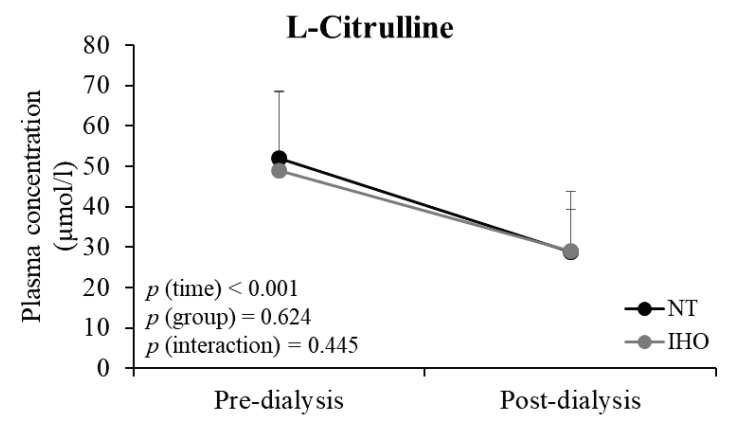

C

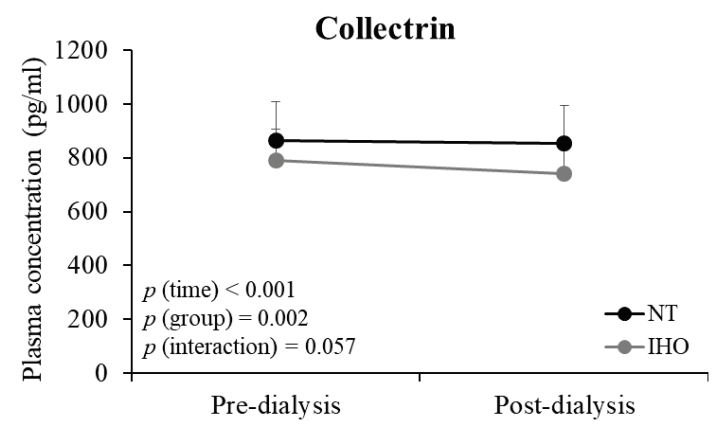

B

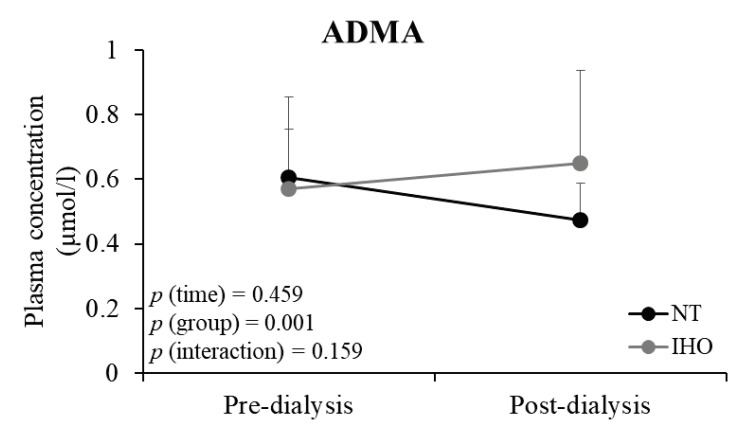

D

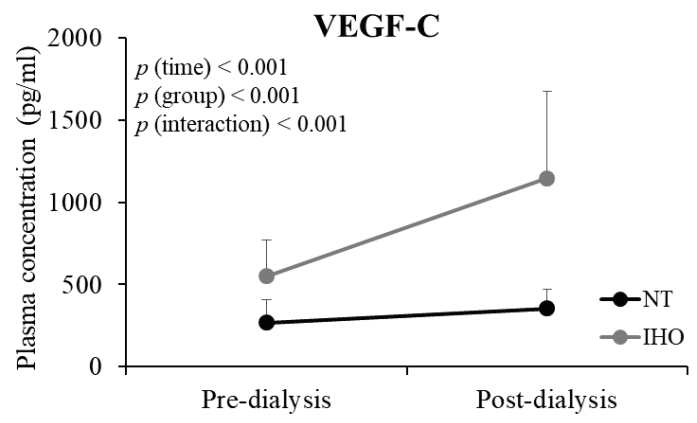

Fig. 4. ADMA, collectrin, VEGF-C and L-Citrulline plasma concentrations in NT and IHO groups. Intradialytic changes of mean plasma concentrations of (A) L-Citrulline, (B) ADMA, (C) collectrin and (D) VEGF-C were measured between pre- and post-dialysis in NT and IHO groups. Values are represented as mean \pm SD. All the data were evaluated by the Two-way MANOVA for repeated measures and represented by 3 types of $p$ values: $p$ (Time) associated with the within subject effect (Time factor, 2 levels, pre and post-dialysis), $p$ (Group) associated with the between subject's effect (Group factor, 2 levels, NT and IHO groups), and the $p$ (Interaction) associated with the group*time interaction term. NT: normotensive; IHO: Intradialytic Hypotension; ADMA: Asymmetric Dimethylarginine; VEGF-C: Vascular Endothelial Growth Factor type C.

\section{Discussion}

Hemodynamic status during HD is subject to multifactorial process related to the HD procedure itself and/or to the patient's profile. IHO is known to be associated with cardiovascular complications and all-cause of mortality (Flythe et al. 2015). Thus, an awareness of the pathophysiology of IHO may help to identify patients who are most susceptible to experience IHO episodes during HD and to prevent its onset. Endothelial impairments constitute a key element in blood pressure control (Dubin et al. 2011). Indeed, an imbalance between vasoconstrictor and vasodilator agents could be responsible in part of the occurrence of IHO. Therefore in this study, we focused on the endothelial micro-environment biomarkers in sixty five patients from the tertiary university hospital Hotel Dieu de France, Beirut.

Excess UF is a known cause of IHO (Flythe et al. 2011, Ok et al. 2016). The removal of extracellular fluid by UF procedure results in 10-30\% decrease in blood volume during HD session duration. IHO occurs when plasma volume falls below a critical threshold (Kooman et al. 2007, Ok et al. 2016). High UF rate is associated with excess mortality due to cardiovascular complications (Assimon et al. 2016). Few studies have 
demonstrated a relationship between the blood volume and the development of IHO (Reeves and Mc Causland 2018), whereas many others disapproved this relation (Krepel et al. 2000, Tonelli et al. 2002, Reeves and Mc Causland 2018), suggesting that other (poorly understood) factors could be involved (Dasselaar et al. 2009). Moreover, a high percentage of IHO episodes was shown to occur during isovolumic dialysis or without UF (Wehle et al. 1979, Dheenan and Henrich 2001). In our study population, the dry weight was frequently assessed and adjusted, moreover, mean UF rate / dry weight was comparable between IHO and NT groups $(13.00 \pm 1.53 \mathrm{ml} / \mathrm{h} / \mathrm{kg}$ vs. $12.99 \pm 3.17 \mathrm{ml} / \mathrm{h} / \mathrm{kg}$ respectively). This suggests that UF rate alone cannot account for IHO episodes.

The majority of our patients were on antihypertensive medications, this could affect the occurrence of IHO, however the similarity of the predialysis blood pressure between both groups and the higher number of antihypertensive medications per patient in the NT group are not in favor of this theory. Moreover, many studies previously addressed this issue, and did not find a correlation between antihypertensive medication used and the occurrence of IHO (Chang 2017).

Tachycardia in response to hypotension did not occur maybe because of the use of $\beta$ blockers drugs or because of autonomic dysfunction, frequent in this population of patients.

Blood pressure regulation depends intimately on the RAAS and the endothelial vasoactive agents balance. Plasma renin, ACE I and aldosterone concentrations were shown to increase in hypotensive dialyzed patients (Moore et al. 1989, Landry and Oliver 2006) or to be compromised (Reeves and Mc Causland 2018). In our study, the more pronounced increase in post-dialysis renin, ACE I and aldosterone plasma concentrations in NT compared to IHO group suggest an impairment of the RAAS response to hypotension in the IHO group. Regarding the higher level of pre-dialysis aldosterone in the IHO group, it may be explained by higher plasma potassium concentration (Schambelan et al. 1980, Sinha and Agarwal 2013).

ACE 2 is identified as a novel actor in the RAAS (Donoghue et al. 2000). The most-important active product of ACE 2 is Ang (1-7), which can be primarily generated via Angiotensin II direct hydroxylation to produce Ang (1-7), or via transformation of angiotensin I to angiotensin 1-9, which is then cleaved to produce Ang
(1-7) (Jiang et al. 2014). Ang (1-7) has broad effects in the cardiovascular system, including vasodilatation and antihypertensive effects (Sampaio et al. 2007). ACE 2 plasma concentration increases in both groups, but in a more marked manner in post-dialysis IHO group, suggesting a role for ACE 2 in inducing vasodilation and hypotension in affected patients.

Endothelial vasoactive agents, particularly ET-1, play an important role in the maintenance of hemodynamic stability during HD. Many studies found unchanged or moderate increase ET-1 plasma levels during HD (Miyauchi et al. 1991, Miyauchi et al. 2012, Deray et al. 1992), while others found a decrease (Raj et al. 2002, El-Shafey et al. 2008). In the present study, plasma ET-1 concentrations showed higher values in post-dialysis IHO group. This could be explained as a compensatory response to the fall of blood pressure.

Even more, an imbalance between NO and ET-1 may affect the development of IHO. NO/ET-1 ratio is a strong predictor of hemodynamic consequence (Raj et al. 2002). NO is a powerful vasodilator, produced by endothelial cells (Amore et al. 1995, Tousoulis et al. 2012). The plasma concentration of NO is difficult to measure because of his short half-life (10-30 s), and it diffuses rapidly through all cell membranes (Furchgott and Vanhoutte 1989). Nevertheless measuring L-Citrulline which is secreted simultaneously and in equal quantity with $\mathrm{NO}$ can be a good tool. In our study, L-Citrulline plasma concentrations are comparable between the two groups in pre- and post-dialysis.

In addition, changes in the plasma concentration of NO inhibitors are also involved in maintaining hemodynamic stability during HD. ADMA is an endogenous competitive inhibitor of NO synthase, and thus may cause endothelial dysfunction (Sibal et al. 2010). Increase in ADMA plasma concentration is associated with angiogenic disorders in hypercholesterolemia, insulin resistance, hypertension and homocysteinemia (Cooke 2003) and an abnormal endothelial regeneration in vitro (Azuma et al. 1995). ADMA is released as a result of proteolysis of proteins containing methylarginine residues. ADMA is hydrolyzed to Citrulline and methylamines by dimethylarginine dimethylaminohydrolases I and II (Vallance and Leiper 2004). A positive correlation was observed between the decrease of ADMA concentration and the occurrence of intradialytic hypotensive episodes (Vallance et al. 1992, Raj et al. 2002, Hewitson et al. 2007). Herein, ADMA plasma concentration increased with $\mathrm{HD}$ in our 
population study. This result can be a compensatory response to the lack of L-Arginine and to avoid further decrease in SBP in this specific group.

Collectrin is a trans-membrane protein expressed in the collecting duct and in the vascular endothelium of conduit and resistance vessels. Collectrin has a role in facilitating the cellular uptake of L-Arginine, substrate of endothelial NO synthase to produce NO ( $\mathrm{Chu}$ and Le 2014). Herein, Collectrin plasma concentration decreased during $\mathrm{HD}$ in both groups, but more markedly in IHO group, resulting in a significant decrease in L-Arginine bioavailability and therefore a decrease in NO synthesis (Cechova et al. 2013). Our results suggest that the decrease of NO release may be a compensatory mechanism trying to protect patient from further dramatic decrease in blood pressure. To the best of our knowledge, this is first study that link collectrin to IHO episodes.

Another important endothelial cell factor is the circulating VEGF-C (Machnik et al. 2009). VEGF-C is essential for endothelial cell growth, cell differentiation, angiogenesis and lymphangiogenesis (Zachary and Gliki 2001, Lahdenranta et al. 2009). Recently, VEGF-C was showed to be implicated in hypervolemia in chronic kidney disease (Sahutoglu et al. 2017). Here, this is the first study to relate VEGF-C to IHO physiopathology.
The higher VEGF-C concentrations observed in post-dialysis in the IHO group may contribute to the development of IHO by enhancing lymphatic drainage of salt inducing a decrease in blood pressure.

In an effort to combine the results and explain the role in IHO genesis, we elaborated a unifying scheme summarizing the explored interactions and pathways (Fig. 5).

As a matter of course, the current study is limited by the sample size, the single facility design and the short duration of follow up. Despite its limitations, the current study is to date the first to assess collectrin and VEGF-C in IHO patients.

In conclusion, the study generated several interesting hypothesis to be considered for future investigations, where endothelial microenvironment dysregulation and VEGF-C impairment may contribute to the pathogenesis of IHO.

\section{Conflict of Interest}

There is no conflict of interest.

\section{Acknowledgements}

This work was supported by the Research Council of the Saint Joseph University - Faculty of Medicine.

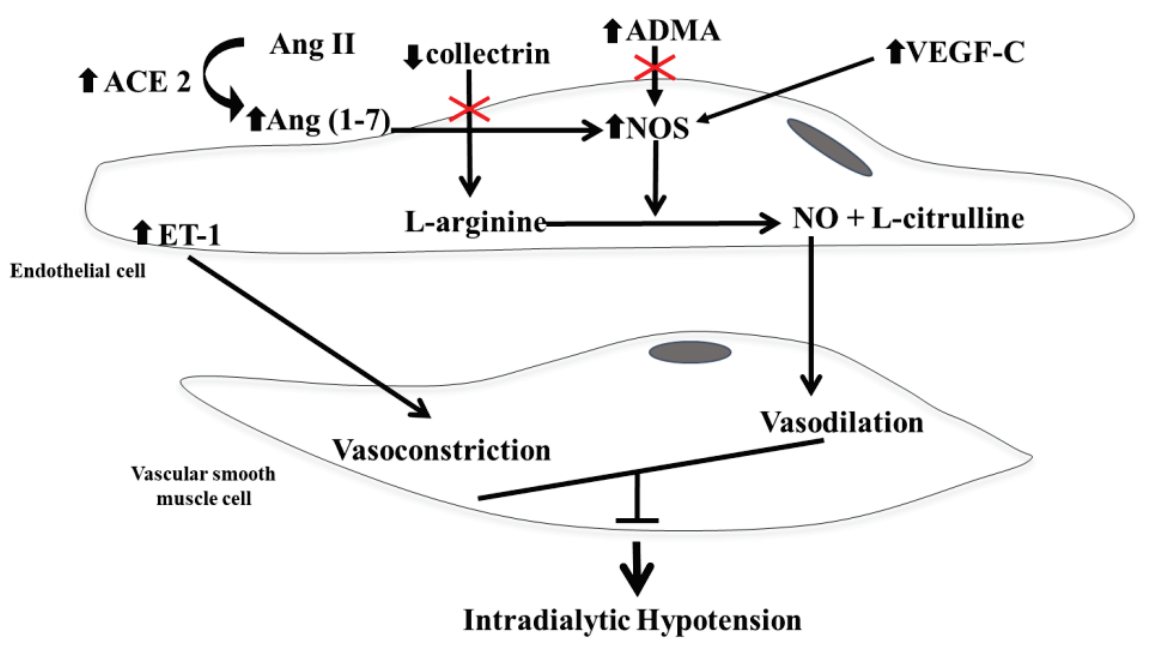

Fig. 5. Proposed scheme summarizing the effect of the studied molecules on IHO pathogenesis. The ACE 2 increase results in Ang (1-7) production which in turn enhances NOS activation and therefore more NO production, despite the decrease of Collectrin. Collectrin decrease, leads to less L-Arginine bioavailability associated with a compensatory increase of ADMA and consequent inhibition in NO synthesis. In parallel, VEGF-C activates NOS. All in all, the vasomotor net effect is going toward more vasodilation status.

\section{References}

AMORE A, BONAUDO R, GHIGO D, ARESE M, COSTAMAGNA C, CIRINA P, GIANOGLIO B, PERUGINI L, COPPO R: Enhanced production of nitric oxide by blood-dialysis membrane interaction. J Am Soc Nephrol 6: 1278-1283, 1995.

ASSIMON MM, WENGER JB, WANG L, FLYTHE JE: Ultrafiltration rate and mortality in maintenance hemodialysis patients. Am J Kidney Dis 68: 911-922, 2016. 
AZUMA H, SATO J, HAMASAKI H, SUGIMOTO A, ISOTANI E, OBAYASHI S: Accumulation of endogenous inhibitors for nitric oxide synthesis and decreased content of L-arginine in regenerated endothelial cells. Br J Pharmacol 115: 1001-1004, 1995.

CECHOVA S, ZENG Q, BILLAUD M, MUTCHLER S, RUDY CK, STRAUB AC, CHI L, CHAN FR, HU J, GRIFFITHS R, HOWELL NL, MADSEN K, JENSEN BL, PALMER LA, CAREY RM, SUNG SS, MALAKAUSKAS SM, ISAKSON BE, LE TH: Loss of collectrin, an angiotensin-converting enzyme 2 homolog, uncouples endothelial nitric oxide synthase and causes hypertension and vascular dysfunction. Circulation 128: 1770-1780, 2013.

CHANG TI: Impact of drugs on intradialytic hypotension: antihypertensives and vasoconstrictors. Semin Dial 30: 532-536, 2017.

CHOU JA, KALANTAR-ZADEH K, MATHEW AT: A brief review of intradialytic hypotension with a focus on survival. Semin Dial 30: 473-480, 2017.

CHOU JA, STREJA E, NGUYEN DV, RHEE CM, OBI Y, INRIG JK, AMIN A, KOVESDY CP, SIM JJ, KALANTAR-ZADEH K: Intradialytic hypotension, blood pressure changes and mortality risk in incident hemodialysis patients. Nephrol Dial Transplant 33: 149-159, 2018.

CHU PL, LE TH: Role of collectrin, an ACE2 homologue, in blood pressure homeostasis. Curr Hypertens Rep 16: 490, 2014.

COOKE JP: NO and angiogenesis. Atheroscler (Suppl 4): 53-60, 2003.

DASSELAAR JJ, SLART RHJA, KNIP M, PRUIM J, TIO RA, MCINTYRE CW, DE JONG PE, FRANSSEN CF: Haemodialysis is associated with a pronounced fall in myocardial perfusion. Nephrol Dial Transplant 24: 604-610, 2009.

DAUGIRDAS JT: Pathophysiology of dialysis hypotension: an update. Am J Kidney Dis 38 (4 Suppl 4): S11-S17, 2001.

DERAY G, CARAYON A, MAISTRE G, BENHMIDA M, MASSON F, BARTHELEMY C, PETITCLERC T, JACOBS C: Endothelin in chronic renal failure. Nephrol Dial Transplant 7: 300-305, 1992.

DHEENAN S, HENRICH WL: Preventing dialysis hypotension: a comparison of usual protective maneuvers. Kidney Int 59: 1175-1181, 2001.

DONOGHUE M, HSIEH F, BARONAS E, GODBOUT K, GOSSELIN M, STAGLIANO N, DONOVAN M, WOOLF B, ROBISON K, JEYASEELAN R, BREITBART RE, ACTON S: A novel angiotensin-converting enzymerelated carboxypeptidase (ACE2) converts angiotensin I to angiotensin 1-9. Circ Res 87: E1-E9, 2000.

DUBIN R, OWENS C, GASPER W, GANZ P, JOHANSEN K: Associations of endothelial dysfunction and arterial stiffness with intradialytic hypotension and hypertension. Hemodial Int 15: 350-358, 2011.

EL-SHAFEY EM, EL-NAGAR GF, SELIM MF, EL-SOROGY HA, SABRY AA: Is there a role for endothelin-1 in the hemodynamic changes during hemodialysis? Clin Exp Nephrol 12: 370-375, 2008.

FLYTHE JE, KIMMEL SE, BRUNELLI SM: Rapid fluid removal during dialysis is associated with cardiovascular morbidity and mortality. Kidney Int 79: 250-257, 2011.

FLYTHE JE, XUE H, LYNCH KE, CURHAN GC, BRUNELLI SM: Association of mortality risk with various definitions of intradialytic hypotension. J Am Soc Nephrol 26: 724-734, 2015.

FURCHGOTT RF, VANHOUTTE PM: Endothelium-derived relaxing and contracting factors. FASEB J 3: 2007-2018, 1989.

GUL A, MISKULIN D, HARFORD A, ZAGER P: Intradialytic hypotension. Curr Opin Nephrol Hypertens 25 : 545-550, 2016.

HEWITSON CL, WHITING MJ, BARBARA JA, MANGONI AA: Acute effects of haemodialysis on biochemical modulators of endothelial function. J Intern Med 262: 571-580, 2007.

INRIG JK, ODDONE EZ, HASSELBLAD V, GILLESPIE B, PATEL UD, REDDAN D, TOTO R, HIMMELFARB J, WINCHESTER JF, STIVELMAN J, LINDSAY RM, SZCZECH LA: Association of intradialytic blood pressure changes with hospitalization and mortality rates in prevalent ESRD patients. Kidney Int 71: 454-461, 2007.

JIANG F, YANG J, ZHANG Y, DONG M, WANG S, ZHANG Q, LIU FF, ZHANG K, ZHANG C: Angiotensinconverting enzyme 2 and angiotensin 1-7: novel therapeutic targets. Nat Rev Cardiol 11: 413-426, 2014. 
K/DOQI WORKGROUP: K/DOQI clinical practice guidelines for cardiovascular disease in dialysis patients. Am J Kidney Dis 45 (4 Suppl 3): S1-S153, 2005.

KOOMAN J, BASCI A, PIZZARELLI F, CANAUD B, HAAGE P, FOUQUE D, KONNER K, MARTIN-MALO A, PEDRINI L, TATTERSALL J, TORDOIR J, VENNEGOOR M, WANNER C, TER WEE P, VANHOLDER R: EBPG guideline on haemodynamic instability. Nephrol Dial Transplant 22 (Suppl 2): ii22-ii44, 2007.

KREPEL HP, NETTE RW, AKÇAHÜSEYIN E, WEIMAR W, ZIETSE R: Variability of relative blood volume during haemodialysis. Nephrol Dial Transplant 15: 673-679, 2000.

LAHDENRANTA J, HAGENDOORN J, PADERA TP, HOSHIDA T, NELSON G, KASHIWAGI S, JAIN RK, FUKUMURA D: Endothelial nitric oxide synthase mediates lymphangiogenesis and lymphatic metastasis. Cancer Res 69: 2801-2808, 2009.

LANDRY DW, OLIVER JA: Blood pressure instability during hemodialysis. Kidney Int 69: 1710-1711, 2006.

LEVINE AB, PUNIHAOLE D, LEVINE TB: Characterization of the role of nitric oxide and its clinical applications. Cardiology 122: 55-68, 2012.

MACHNIK A, NEUHOFER W, JANTSCH J, DAHLMANN A, TAMMELA T, MACHURA K, PARK JK, BECK FX, MÜLLER DN, DERER W, GOSS J, ZIOMBER A, DIETSCH P, WAGNER H, VAN ROOIJEN N, KURTZ A, HILGERS KF, ALITALO K, ECKARDT KU, LUFT FC, KERJASCHKI D, TITZE J: Macrophages regulate salt-dependent volume and blood pressure by a vascular endothelial growth factor-C-dependent buffering mechanism. Nat Med 15: 545-552, 2009.

MCINTYRE CW: Recurrent circulatory stress: the dark side of dialysis. Semin Dial 23: 449-451, 2010.

MIYAUCHI T, SUZUKI N, KURIHARA T, YAMAGUCHI I, SUGISHITA Y, MATSUMOTO H, GOTO K, MASAKI T: Endothelin-1 and endothelin-3 play different roles in acute and chronic alterations of blood pressure in patients with chronic hemodialysis. Biochem Biophys Res Commun 178: 276-281, 1991.

MIYAUCHI Y, SAKAI S, MAEDA S, SHIMOJO N, WATANABE S, HONMA S, KUGA K, AONUMA K, MIYAUCHI T: Increased plasma levels of big-endothelin-2 and big-endothelin-3 in patients with end-stage renal disease. Life Sci 91: 729-732, 2012.

MOORE TJ, LAZARUS JM, HAKIM RM: Reduced angiotensin receptors and pressor responses in hypotensive hemodialysis patients. Kidney Int 36: 696-701, 1989.

OK E, ASCI G, CHAZOT C, OZKAHYA M, MEES EJ: Controversies and problems of volume control and hypertension in haemodialysis. Lancet 388: 285-293, 2016.

PALMER BF, HENRICH WL: Recent advances in the prevention and management of intradialytic hypotension. $J A m$ Soc Nephrol 19: 8-11, 2008.

RAJ DSC, VINCENT B, SIMPSON K, SATO E, JONES KL, WELBOURNE TC, LEVI M, SHAH V, BLANDON P, ZAGER P, ROBBINS RA: Hemodynamic changes during hemodialysis: role of nitric oxide and endothelin. Kidney Int 61: 697-704, 2002.

REEVES PB, MC CAUSLAND FR: Mechanisms, clinical implications, and treatment of intradialytic hypotension. Clin $J$ Am Soc Nephrol 13: 1297-1303, 2018.

RONCO C, BRENDOLAN A, MILAN M, RODEGHIERO MP, ZANELLA M, LA GRECA G: Impact of biofeedbackinduced cardiovascular stability on hemodialysis tolerance and efficiency. Kidney Int 58: 800-808, 2000.

SAHUTOGLU T, SAKACI T, HASBAL NB, AHBAP E, KARA E, SUMERKAN MC, SEVINC M, AKGOL C, KOC Y, BASTURK T, UNSAL A: Serum VEGF-C levels as a candidate biomarker of hypervolemia in chronic kidney disease. Medicine (Baltimore) 96: e6543, 2017.

SAMPAIO WO, SOUZA DOS SANTOS RA, FARIA-SILVA R, DA MATA MACHADO LT, SCHIFFRIN EL, TOUYZ RM: Angiotensin-(1-7) through receptor Mas mediates endothelial nitric oxide synthase activation via Akt-dependent pathways. Hypertension 49: 185-192, 2007.

SCHAMBELAN M, SEBASTIAN A, BIGLIERI EG: Prevalence, pathogenesis, and functional significance of aldosterone deficiency in hyperkalemic patients with chronic renal insufficiency. Kidney Int 17: 89-101, 1980.

SIBAL L, AGARWAL SC, HOME PD, BOGER RH: The role of asymmetric dimethylarginine (ADMA) in endothelial dysfunction and cardiovascular disease. Curr Cardiol Rev 6: 82-90, 2010.

SINHA AD, AGARWAL R: Chronic renal disease progression: treatment strategies and potassium intake. Semin Nephrol 33: 290-299, 2013. 
TONELLI M, ASTEPHEN P, ANDREOU P, BEED S, LUNDRIGAN P, JINDAL K: Blood volume monitoring in intermittent hemodialysis for acute renal failure. Kidney Int 62: 1075-1080, 2002.

TOUSOULIS D, KAMPOLI AM, TENTOLOURIS C, PAPAGEORGIOU N, STEFANADIS C: The role of nitric oxide on endothelial function. Curr Vasc Pharmacol 10: 4-18, 2012.

VALLANCE P, LEIPER J: Cardiovascular biology of the asymmetric dimethylarginine:dimethylarginine dimethylaminohydrolase pathway. Arterioscler Thromb Vasc Biol 24: 1023-1030, 2004.

VALLANCE P, LEONE A, CALVER A, COLLIER J, MONCADA S: Accumulation of an endogenous inhibitor of nitric oxide synthesis in chronic renal failure. Lancet 339: 572-575, 1992.

WEHLE B, ASABA H, CASTENFORS J, FÜRST P, GUNNARSSON B, SHALDON S, BERGSTRÖM J: Hemodynamic changes during sequential ultrafiltration and dialysis. Kidney Int 15: 411-418, 1979.

ZACHARY I, GLIKI G: Signaling transduction mechanisms mediating biological actions of the vascular endothelial growth factor family. Cardiovasc Res 49: 568-581, 2001. 